\title{
MOVIMENTOS PENDULARES E INTEGRAÇÃO REGIONAL NO VALE DO PARAÍBA E LITORAL NORTE NO ESTADO DE SÃO PAULO: UMA ANÁLISE A PARTIR DOS CENSOS DEMOGRÁFICOS DE 2000 E 2010
}

\author{
Lidiane M. Maciel \\ Universidade do Vale do Paraíba \\ Programa de Pós-graduação em Planejamento urbano e Regional, São José dos Campos, SP, Brasil \\ lidiane@univap.br \\ Cilene Gomes \\ Universidade do Vale do Paraíba, Programa de Pós-graduação em Planejamento urbano e Regional \\ São José dos Campos, SP, Brasil \\ cilenegomes2011@gmail.com \\ Leandro Blanque Becceneri \\ Universidade Estadual de Campinas \\ Programa de Pós-graduação em Demografia, Campinas, SP, Brasil \\ leandrobecc@hotmail.com
}

\begin{abstract}
RESUMO
Este artigo objetiva discutir os movimentos pendulares e a integração regional (LOBO, et. al, 2017; OJIMA, 2011) no contexto da organização espacial da Região Metropolitana do Vale do Paraíba e Litoral Norte (RMVPLN) - São Paulo. A metodologia se baseia na análise de Microdados dos Censos Demográficos 2000 e 2010, a fim de realizar uma comparação possível da problemática da mobilidade pendular na RMVPLN. Os resultados e a conclusão da reflexão se inclinarão a ponderar sobre o movimento populacional em sua conexão com os movimentos da economia, especialmente do mercado de trabalho, e de transformação socioespacial, que em boa razão se correlacionam com a hipótese sobre a influência das dinâmicas de desconcentração metropolitana nos processos de urbanização e integração regional.
\end{abstract}

Palavras-chave: Movimento pendular. Região Metropolitana do Vale do Paraíba e Litoral Norte. Integração regional. Urbanização. População.

\section{COMMUTING AND REGIONAL INTEGRATION IN THE VALE DO PARAÍBA E LITORAL NORTE: AN ANALYSIS FROM THE DEMOGRAPHIC CENSUS 2000 AND 2010}

\begin{abstract}
This article discusses the relationship between commuting and regional integration (LOBO, et al., 2017; OJIMA, 2011), in the context of the spatial organization of the Metropolitan Region of Vale do Paraíba and Litoral Norte (RMVPLN) - São Paulo. The methodology is based on the analysis of the microdata from the Demographic Census of 2000 and 2010, in order to make a comparison of the problem of commuting at the RMVPLN. The results and conclusion indicated the population movement in connection with the movements of the economy and socio-spatial transformation, reaffirming the hypothetical influences of the dynamics of metropolitan deconcentration in the process of urbanization and regional integration.
\end{abstract}

Keywords: Commuting. Metropolitan Area of Vale do Paraíba and Litoral Norte. Regional integration. Urbanization. Population. 


\title{
INTRODUÇÃO
}

$\mathrm{Na}$ atualidade a questão da integração regional e, nela implícita, a problemática das relações interregionais e intermunicipais são pontos fundamentais no estudo da organização do espaço urbanometropolitano e regional. Segundo Santos (1996) a integração pode ser analisada sob o ponto de vista funcional e territorial, ou seja, a partir das relações verticais e horizontais, no primeiro caso, por meio de fluxos reguladores, que asseguram o funcionamento global da sociedade e da economia, e respectivamente, pelas interrelações horizontais que se dão por meio de uma estrutura social e produtiva com suas ofertas e demandas em potencial.

No contexto dos desdobramentos da institucionalização da Região Metropolitana do Vale do Paraíba e Litoral Norte (RMVPLN) ${ }^{1}$ no Estado de São Paulo, tornou-se relevante a necessidade de reconhecer e analisar as formas pelas quais o princípio da integração (SILVA NETO, 2010), prenunciado pelo Estatuto da Metrópole (BRASIL, 2015), deverá se objetivar no processo de planejamento e reorganização do espaço urbano-regional, ora centrado nas discussões em torno da elaboração do Plano de Desenvolvimento Urbano Integrado (PDUI). Deste modo, considera-se que os diferentes fluxos de pessoas, informações, capitais e produtos definem as dinâmicas sociais e econômicas de integração funcional e territorial e são propriedades constitutivas da organização espacial (SANTOS, 1996; CASTELLS, 1999) em qualquer escala de observação. Eles são elementos indicativos das relações entre os diferentes municípios de uma região e do grau de polaridade e intensidade de interdependências. As formas de movimento são, por isso, passíveis de análise para inferências sobre o padrão de integração da rede urbana regional, dado pelas densidades e rarefações de relações interurbanas em precisos momentos da história.

Nos estudos sobre a transformação e estruturação de espaços metropolitanos, as dinâmicas do movimento populacional têm sido um dos objetos de investigação dos mais valorizados e frequentes. Uma análise de alguns exemplares da produção do Observatório das Metrópoles (SILVA, 2012; CLEMENTINO; PESSOA, 2009) das últimas décadas, dentre outros núcleos de estudo e pesquisa, como do Núcleo de Estudos de População (NEPO/UNICAMP), por meio de diferentes trabalhos de Cunha (2013; 2015a; 2019) e, mesmo, a da antiga EMPLASA (1974-2019), demonstra a importância dessa análise. De fato, conforme apontam Lobo et al. (2017):

\begin{abstract}
dentre as variáveis que tradicionalmente servem de parâmetro para a identificação do grau de integração intermunicipal metropolitana, destacam-se os chamados movimentos pendulares que, além da intensidade e direção dos fluxos populacionais diários no tecido metropolitano, refletem a dinâmica e organização do mercado laboral e educacional. A mobilidade intrametropolitana configura-se, portanto, como um indicador sensível ao grau de interação municipal no espaço regional, refletindo, dessa forma, a própria densidade social do espaço metropolitano. (LOBO et al., 2017, p.322).
\end{abstract}

No presente artigo, considera-se igualmente que, dentre os fluxos econômicos e sociais, os movimentos populacionais e, particularmente, a pendularidade representa, de modo singular, as conexões geográficas entre regiões e municípios. Os movimentos pendulares se definem pelos deslocamentos diários ou rotineiros de população de um município para outro, normalmente orientados pela busca por trabalho/renda, estudo e acesso a diferentes serviços públicos e particulares. Desse modo, a análise da dimensão sociodemográfica e dos movimentos populacionais constitui pré-condição essencial para o apontamento de tendências da reorganização do espaço urbano-regional e a inferência de demandas de planejamento. A distribuição populacional e a dinâmica dos movimentos populacionais são fenômenos elementares para futuras investigações em vista da identificação e tratamento de distintas problemáticas de interesse comum aos municípios integrantes da região. O que supõe certas insuficiências e dificuldades dos municípios, bem como os potenciais de cooperação para a estruturação de novas provisões a serem ofertadas, tais como a de oportunidades de trabalho, serviços públicos e equipamentos urbanos e regionais.

No seu conjunto, as populações são agentes da produção social do espaço, mediante o uso e a ocupação do solo que promovem, o que é indissociável da questão fundiária e da habitação, das infraestruturas, do desenvolvimento econômico, dos equipamentos de atendimento social, da vida

${ }^{1}$ Lei Complementar no 1.166, de 9 de janeiro de 2012. (Estado de São Paulo).

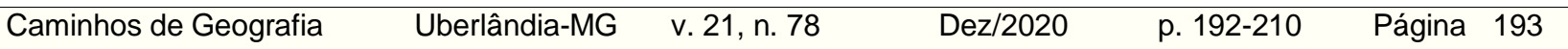


cultural e uso do tempo livre, do planejamento, enfim. Se a centralidade do planejamento deve estar nas pessoas (SANTOS, 2000) e nas demandas sociais urgentes de serem enfrentadas, as análises demográficas tornam-se cruciais, e relevantes, sobretudo em contextos tão desiguais quanto os de nossa formação socioespacial, em toda região e lugar do país.

A partir das considerações anteriores, o artigo tem por objetivo geral abordar a questão da integração e da organização da rede urbana regional, a partir de estudo demográfico e, mais especificamente, dos movimentos pendulares (OJIMA, 2011). Tais questões e dinâmicas representam e indicam as insuficiências locais e regionais, ligadas às polarizações do sistema urbano e o respectivo desequilíbrio ou defasagens quanto às condições das municipalidades de promoverem o seu processo de planejamento e organização para a provisão do que lhe é socialmente necessário nos âmbitos diversos das condições gerais ao desenvolvimento social, urbano e regional. A metodologia é descritiva e comparativa, busca a partir dos dados dos Censos Demográficos 2000 e 2010, elementos para o aprofundamento das reflexões teóricas. Em recorrência a essa ordem de ideias, o desenvolvimento do artigo organiza-se em três seções. Na primeira discute-se o processo de metropolização e a questão das regiões metropolitanas; na segunda a integração territorial e organização da rede urbana (BESSA, 2012) regional e aspectos gerais sociodemográficos, e por fim, a análise das relações entre integração regional e os movimentos pendulares na RMVPLN, considerando a mobilidade vinculada ao trabalho.

\section{METROPOLIZAÇÃO E A QUESTÃO DAS REGIÕES METROPOLITANAS}

Diversos fenômenos estão associados com o termo metrópole e metropolização. É difícil encontrar uma definição única e simples, o que leva a indagar se o emprego dessas expressões é prova da riqueza ou limitação desses conceitos. Parece, então, que produzir uma definição abrangente e significativa é algo complexo, como demonstrado por grande número de trabalhos relacionados a esse tema (ASCHER, 1995; CUNHA, 2013; SILVA, 2013; LENCIONE, 2017). O que se observa nessa literatura é a tentativa de compreender os múltiplos aspectos da metrópole, mostrando as consequências do processo de metropolização no contexto do capitalismo periférico e pós-fordista a partir da década de 1970.

Em termos históricos, é a partir da década de 1950 que se nota mais frequentemente no país uma tendência à aglomeração da população e da urbanização. A partir desse período, as cidades com população superior a um milhão, que eram duas em 1960, são cinco em 1970, dez em 1980, doze em 1991 (SANTOS, 1993) e dezessete em 2010 (IBGE, 2010).

Deste modo, a discussão sobre o tema perpassa a definição do que seria uma metrópole em diferentes tradições. Tal estrutura que no Brasil se deu de forma rápida e conjunta com a urbanização do país, como expresso por Silva (2012, p.28), ao mostrar que "tivemos uma urbanização rápida e uma metropolização precoce", tornando a metrópole diferente de uma cidade grande comum.

No Brasil, as metrópoles são hoje o "locus por excelência das relações sociais e econômicas" (Santos, 1993, p. 75) mais dinâmicas e integradas à globalização. Os processos que a constituem e dela irradiam convergem na metropolização do espaço, um fenômeno intrinsecamente ligado às determinações históricas, econômicas e sociais do país, que incidiram espacialmente mediante a constituição de grandes concentrações urbanas, populacionais, de riqueza e pobreza, expressivas de grande diversidade sociodemográfica, econômica e cultural.

Por conseguinte, cabe então abordar a interligação das variáveis demográficas com o processo de urbanização e metropolização. Destaca-se, então, que a migração é um componente do crescimento demográfico que difere da fecundidade e da mortalidade. Em relação aos movimentos migratórios, Nazareth (2004) aponta que suas variações no espaço e no tempo dependem de "fatores sociais e econômicos complexos, de natureza interna e externa, em relação à unidade espacial em estudo" ( $p$. 253). Com a diminuição dos fluxos migratórios de longa distância, conforme resultados apresentados por Ojima (2011) e Cunha (2015b), especialmente a partir dos anos de 1980, a migração urbano-urbano (intrametropolitana; intermunicipal) passa a ser importante enquanto força social de estruturação do processo de metropolização das aglomerações urbanas (BAENINGER, 2011). 
Em paralelo ao processo das migrações intrametropolitana e intermunicipal se apresentam também os movimentos pendulares na escala intrametropolitana que permite observar a produção do espaço urbano, evidenciando a atuação dos diversos agentes, como o governo, os detentores de capital, ou seja, os ativos e passivos detidos pelos indivíduos privados e institucionais (PIKETTY, 2013) e a sociedade civil.

Ojima (2012) em importante estudo sobre as áreas metropolitanas e os movimentos pendulares, afirma que a análise das aglomerações urbanas é importante para o entendimento das dinâmicas intrarregionais, pois nelas se observam dinâmicas demográficas, como o movimento pendular, expressando a expansão dos espaços de vida da população. A sede dessas aglomerações urbanas exerce influência significativa "no polo regional aglutinador das movimentações financeiras e ainda do desenvolvimento econômico" (OJIMA, 2012, p. 627), caso de São José dos Campos, por exemplo.

Nesse contexto, cabe destacar a implantação legal das regiões metropolitanas, um ponto importante das discussões atuais sobre o planejamento regional. No período em que esse processo teve início, na década de 1970, o Brasil vivia sob um regime militar (1964-1985), com uma legislação construída de forma excludente e vertical, diferente da democrática. As áreas metropolitanas se inseriram como fundamentais no desenvolvimento do modelo econômico vigente, sendo estratégicas para o Estado Militar (SOUZA, 2003). Desde 1988, a criação dessas áreas depende da aprovação de uma Lei Estadual específica, pois a Constituição Federal atribuiu aos Estados a responsabilidade pela criação de regiões metropolitanas, sem deixar claro, porém, como seria coordenada a dinâmica dessas regiões entre os três níveis de governo. A nova Constituição legitimou o federalismo como o sistema democrático brasileiro e incluiu o município como uma instituição federativa, reconhecendo sua autonomia política, administrativa e financeira. Portanto, verifica-se que naquele período foi rompido o modelo centralizador herdado do Regime Militar (SOUZA, 2003).

Percebe-se então, que o arranjo metropolitano se tornou um ambiente complexo e problemático para o planejamento e a implantação de políticas públicas que perpassem as três esferas administrativas. A Região Metropolitana do Vale do Paraíba e Litoral Norte (RMVPLN) criada pela Lei complementar no 1.166, de 9 de janeiro de 2012 (Estado de São Paulo) é uma importante área de "passagem" no Estado de São Paulo, composta por 39 municípios com diferentes realidades e heterogeneidades, conforme demonstrado por Cunha, Silva e Becceneri (2019). A região concentra atualmente mais de 2,5 milhões de habitantes, produzindo 4,8\% do PIB paulista em 2016 (IBGE, 2018). A urbanização nessa região foi bastante intensa desde os anos 1950 e se relaciona diretamente ao significativo desenvolvimento econômico de municípios como São José dos Campos, Taubaté, Jacareí, Pindamonhangaba, Caraguatatuba e Guaratinguetá, cidades que concentram a maior parte da população da região. Alguns aspectos da organização socioespacial delas podem ser ressaltados para melhor contextualização de sua dimensão sociodemográfica e das dinâmicas populacionais pendulares.

\section{INTEGRAÇÃO TERRITORIAL E ORGANIZAÇÃO DA REDE URBANA REGIONAL}

Para a compreensão da dimensão sociodemográfica do espaço regional e da dinâmica recente dos movimentos populacionais, as condições de integração territorial observadas por meio dos sistemas viários e de informação e comunicação são fundamentais. Historicamente, a constituição dos primeiros caminhos terrestres e marítimos e dos sistemas ferroviários e, sobretudo, dos rodoviários, levou, em sucessivos períodos da história regional, a distintos estágios de integração territorial e dinamização funcional da vida econômica, social e urbana. Os impactos da revolução científico-tecnológica (SANTOS, 1996) nos decênios posteriores à Segunda Guerra Mundial e da sociedade da informação e comunicação de nossos dias, ocasionam igualmente remodelações sócio territoriais diversas, advindas, em boa medida, desse novo meio de integração social constituído, o que torna possível interrelações numerosas e intensificadas no tempo e espaço.

$\mathrm{Na}$ escala de organização do espaço regional, essas condições territoriais de acessibilidade física e social favoreceram, a partir da década de 1950 e, sobretudo, diante dos decênios de 1970 e 1980, uma reorganização produtiva de base industrial e científico-tecnológica. Os movimentos populacionais e o desenvolvimento da economia e da urbanização regional, favoreceram em grande parte o 
adensamento e expansão de áreas urbanizadas e dos serviços de apoio às populações e aos espaços produtivos (LAMPARELLI; CAMARGO; GEORGE, 2007).

Para Santos (1993), tais condições tornaram possível a dissolução metropolitana e a desmetropolização, com um relativo maior dinamismo das cidades intermediárias no sistema urbano regional. É o caso das relações de interdependência entre a metrópole paulistana e a região do Vale do Paraíba, desencadeando o desenvolvimento progressivo de cidades do Eixo Dutra, com destaque para as principais sedes regionais, São José dos Campos, Taubaté, Guaratinguetá e Cruzeiro, sobretudo para as duas primeiras. E mais recentemente, para as tendências a conurbações e dinamização de outras cidades, como Jacareí, Pindamonhangaba, Aparecida e Lorena.

A Figura 1 representa a organização da Região do Vale do Paraíba e Litoral Norte e, nela, pode-se observar a estrutura viária mais ramificada e adensada ao longo da Rodovia Presidente Dutra, assim como a linearidade da urbanização regional representada pela localização das principais cidades assentadas na calha do Rio Paraíba e nos arredores daquela rodovia.

Figura 1 - Organização territorial da região do Vale do Paraíba e Litoral Norte (2013).

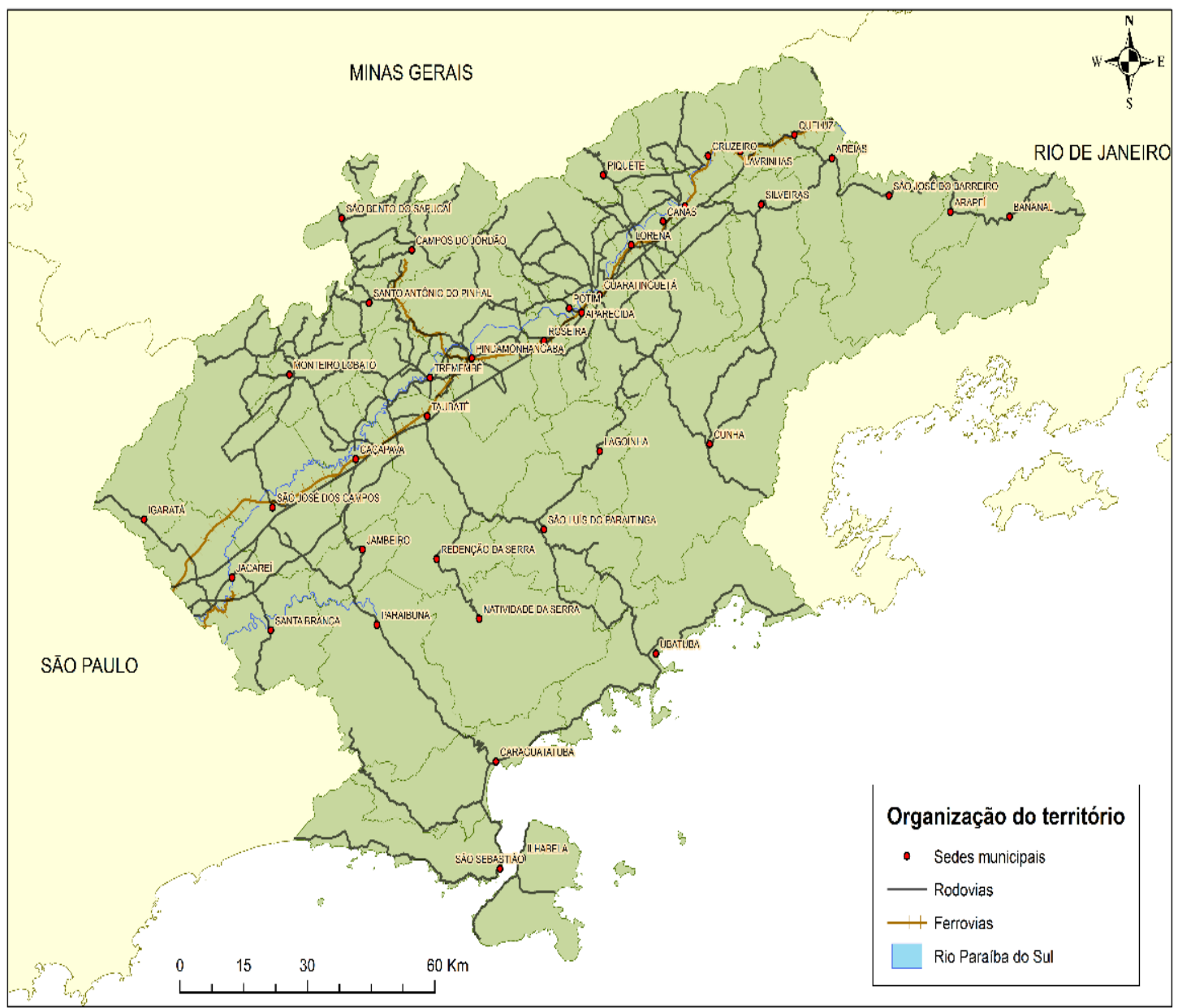

Fonte - Departamento Nacional de Infraestrutura de Transporte (2013).

Presta-se ainda a Figura (1) como apoio para evidenciar a estruturação socioespacial desequilibrada e concentrada da rede urbana regional. Somente nos 16 municípios atravessados pela Rodovia Presidente Dutra, em 2010, concentrava-se 93,5\% dos 2.131.296 habitantes urbanos da região. Consequentemente, é ao longo desse eixo viário que se verifica, em sua conformação linear, o mais expressivo dinamismo econômico-produtivo e da urbanização regional. O que subentende, na análise de Silva Neto (2002), a realidade de um espaço intrarregional e urbano de mais alta integração técnicoeconômica. Nesse espaço, os sistemas técnicos de integração territorial se aliam às dinâmicas

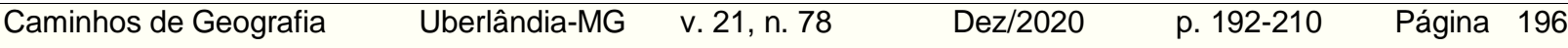


econômicas mais produtivas constituindo novos territórios do mercado e do desenvolvimento urbanoregional e, todavia, engendrando situações de agravamento das contradições socioespaciais, à base de uma distribuição desigual de populações, recursos, riquezas e condições gerais para a realização produtiva e social.

\section{DIMENSÃO SOCIODEMOGRÁFICA DO ESPAÇO REGIONAL}

O desenvolvimento econômico, e a consequente evolução populacional da RMVPLN, faz parte de um movimento maior que, intensificado nos últimos quarenta anos, descentrou a metrópole paulistana criando por todo o território estadual uma área de expansão econômica (NEGRI, 1996; ROLNIK; KLINK, 2011) e uma nova amplitude de redistribuição da população. A discussão sobre a "Macrometrópole paulista", originada no final dos anos 1970 e promovida recentemente a partir do Plano de Ação Macrometropolitana (EMPLASA, 2014) junto ao debate teórico-empírico sobre metropolização, regiões metropolitanas e o Estatuto da Metrópole (BRASIL, 2015), deixa poucas dúvidas sobre a complementaridade existente entre a Região Metropolitana de São Paulo e as aglomerações urbanas próximas, tais como as do Vale do Paraíba (CUNHA, 2015a).

Nesse contexto de interdependências regionais e urbanas, a região reforçou suas interligações com pelos menos dois outros Estados brasileiros: o Rio de Janeiro e Minas Gerais. Destacando-se por sua dinâmica econômico-produtiva ancorada em segmentos industriais nacionais e internacionais, ligados aos ramos aeronáutico, automobilístico e eletroeletrônico, em seu complexo de instituições e empresas de base científico e tecnológica e em sua estrutura diversificada de comércios e serviços.

O desenvolvimento econômico da RMVPLN vem acompanhado de um processo de urbanização, que se intensifica desde os anos de 1970 e 1980 (ANDRADE, 2019), e que pode ser evidenciado, para o decênio de 2000 até 2010, pelo grau de urbanização, que é um indicador útil para inferir sobre a adequação e funcionamento da rede de serviços sociais e da infraestrutura urbana.

A análise do grau de urbanização (Figura 2) mostra que uma das características mais importantes da RMVPLN é sua grande heterogeneidade, evidenciada pelas diferenças em termos relativos da população urbana residente nos municípios. No comparativo entre os dois anos analisados, nota-se que as mudanças não foram consideráveis. Tanto em 2000 quanto em 2010, dos 39 municípios da região, 18 apresentavam grau de urbanização maior que 85\%, com destaque para o Litoral Norte. Um ponto importante a ser observado é que os municípios localizados no traçado da rodovia Presidente Dutra, juntamente àqueles do Litoral Norte, apresentam valores elevados de grau de urbanização. Já os localizados na região do Alto Paraíba apresentam valores bem menores do indicador.

Figura 2 - Grau de urbanização dos municípios da Região Metropolitana do Vale do Paraíba e Litoral Norte (2000 e 2010)

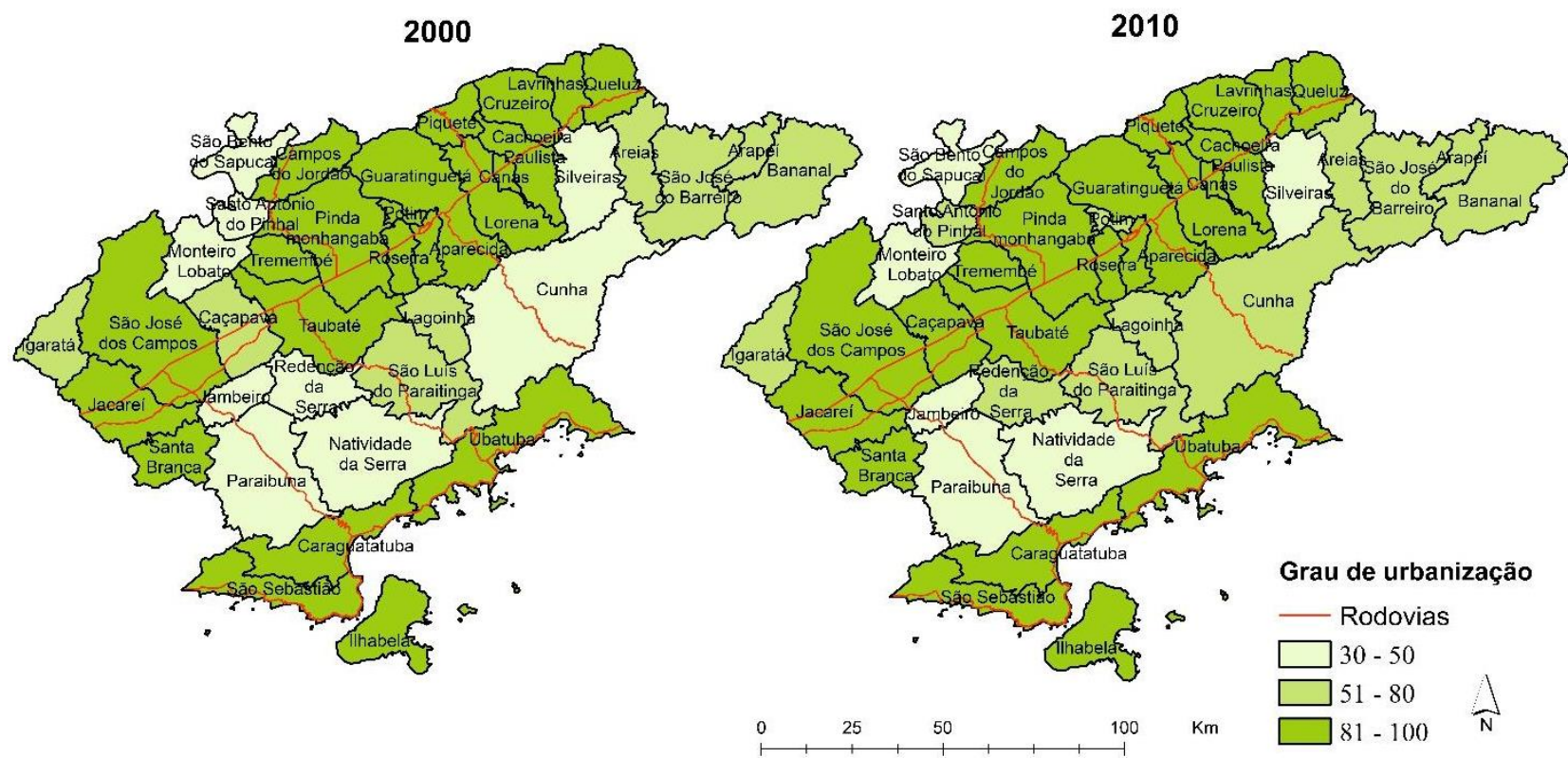

Fonte - Censos demográficos do IBGE de 2000 e 2010. Elaboração própria. 
No que se refere à evolução total da população entre os municípios médios e grandes, destaca-se São José dos Campos, Taubaté, Jacareí, Pindamonhangaba e Caraguatatuba. A Tabela 1 apresenta essa estatística.

Tabela 1 - Evolução da população dos municípios de São José dos Campos, Taubaté, Pindamonhangaba, Caraguatatuba, Jacareí; 1980 e 2020.

\begin{tabular}{lcc}
\hline \multicolumn{1}{c}{ MUNICÍPIO } & $\mathbf{1 9 8 0}$ & $\mathbf{2 0 2 0}$ \\
SÃO JOSÉ DOS CAMPOS & 285.587 & 710.654 \\
TAUBATÉ & 168.722 & 307.361 \\
JACAREÍ & 115.100 & 227.945 \\
PINDAMONHANGABA & 69.149 & 163.611 \\
CARAGUATATUBA & 33.563 & 116.106
\end{tabular}

Fonte - Fundação SEADE.

Quando considerados os aspectos demográficos, como a da estrutura etária da RMVPLN, observa-se, pelas pirâmides etárias, o envelhecimento da população ao longo das décadas. Conforme a Figura 3 , o formato piramidal de 1980 é substituído por um formato de "jarro" em 2010. Esse fenômeno também é demonstrado no trabalho de Cunha, Silva e Becceneri (2019), por meio da espacialização do índice de envelhecimento para os municípios da região.

Aqui, as pirâmides são utilizadas para auxiliar na compreensão do histórico de fecundidade, mortalidade e migração da população do Vale, assim como para fornecer indicações sobre sua etapa na transição demográfica (ALVES, 2008) e a provável influência da estrutura de idade e sexo nas futuras alterações populacionais da região. É possível observar nesse contexto que os efeitos da transição demográfica, em curso no Brasil pelo menos desde o final da década de 1940 (VASCONCELOS; GOMES, 2012), também são observados na RMVPLN, com a população tornandose mais envelhecida, à medida que diminui o número de crianças e jovens, estreitando a base da pirâmide, e aumentando o número de idosos, alargando o topo, especialmente no ano de 2010. É importante destacar, porém, a predominância ainda de população relativamente jovem, com suas maiores concentrações entre os 15 e 29 anos, como indicam as pirâmides da Figura 3.

Cabe ressaltar que a transição demográfica apresenta efeitos e consequências na configuração dos espaços urbanos. No último Censo Demográfico (2010), observou-se o aumento do número de domicílios unipessoais, habitados principalmente por idosos. Tal configuração é observada de forma particular nas áreas centrais das grandes cidades (NAKANO, 2015). Esse aspecto é observado em regiões onde já ocorreu a transição de regimes de altas taxas de fecundidade e de mortalidade, para um regime de baixas taxas de fecundidade e mortalidade, em que há um baixo crescimento vegetativo, sendo cada vez mais importante o movimento da população (migração e movimentos pendulares), tornando-se necessário compreender como a população está distribuída no espaço.

Figura 3 - Pirâmides etárias da Região Metropolitana do Vale do Paraíba e Litoral Norte, 1980-2010.
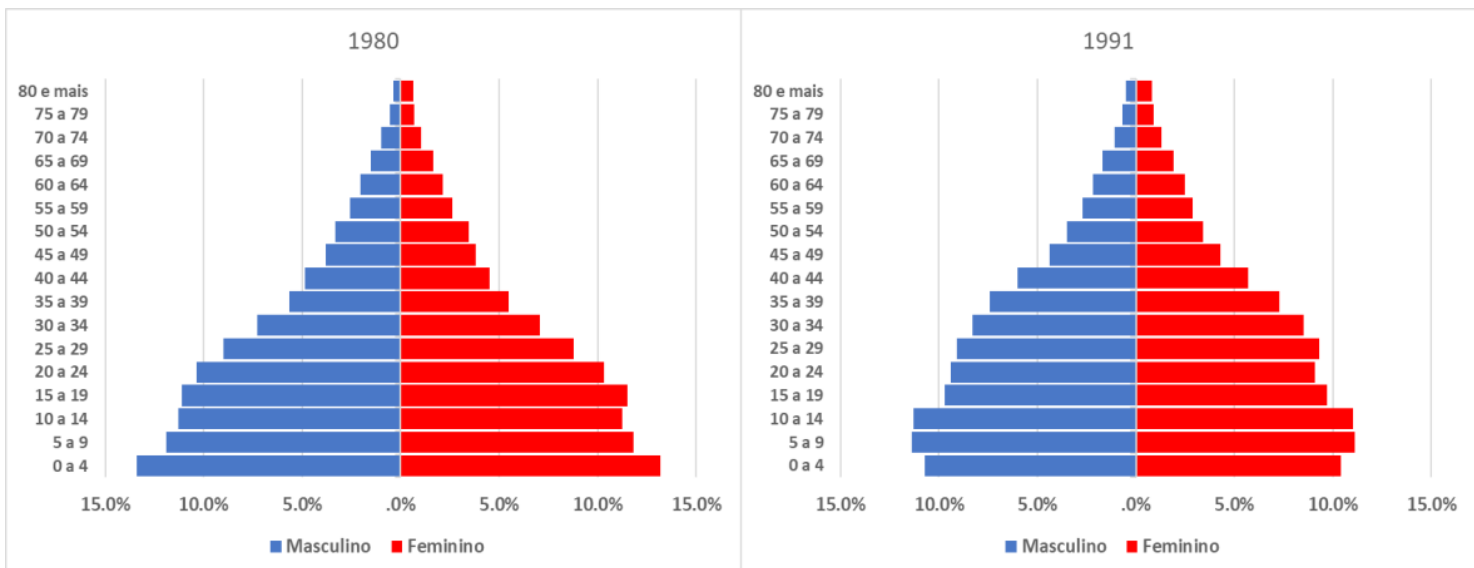


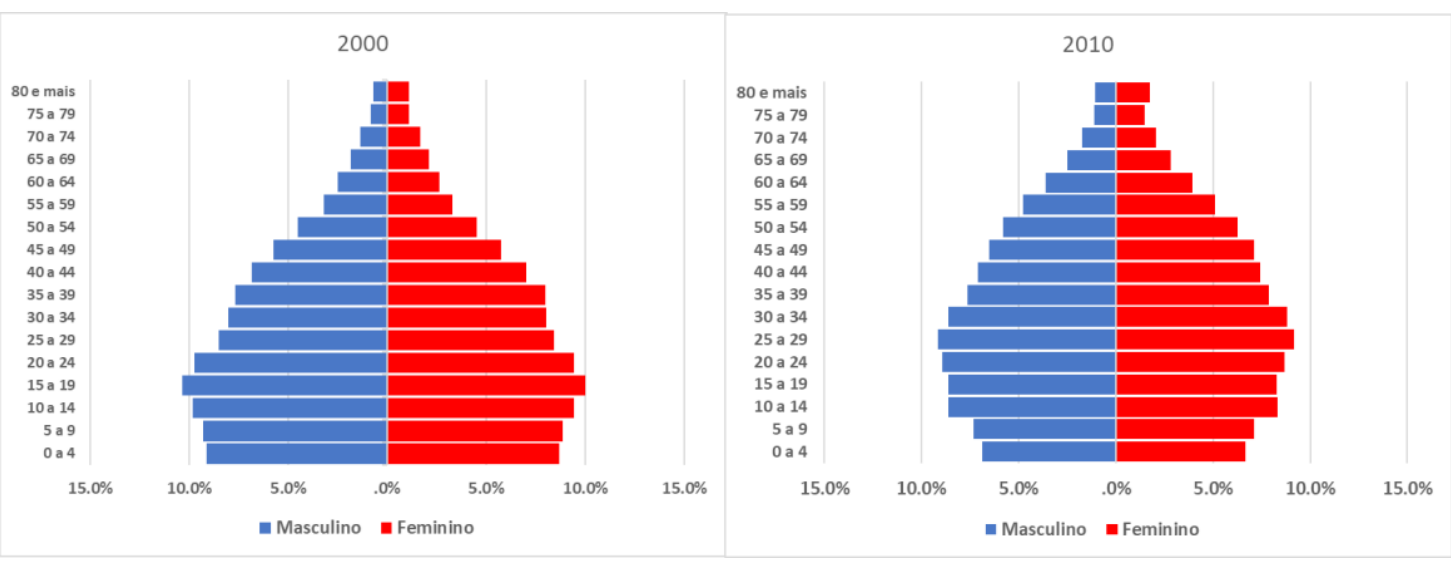

Fonte - Censos demográficos do IBGE de 1980, 1991, 2000 e 2010. Elaboração própria.

É válido destacar, a partir da Figura 3, que nos últimos trinta anos a população da RMVPLN cresceu, sobretudo, em função das migrações interestaduais e intermunicipais. Os Estados que mais perderam população para a região foram: Minas Gerais, Paraná, Rio de Janeiro e Bahia. Quando se refere à contribuição dos migrantes do próprio Estado de São Paulo, para a evolução da população da RMVPLN, destaca-se migrantes vindos de diversos municípios da Região Metropolitana de São Paulo e Campinas. No caso de São José dos Campos, por exemplo, o Censo Demográfico de 2010 indicou que $45 \%$ da população residente no município era composta por moradores que vieram de outros municípios. A Tabela 2, abaixo, mostra a participação da migração no total do crescimento populacional da região entre os anos de 1991 e 2010:

Tabela 2 - Participação da migração no total do crescimento populacional. Região Metropolitana do Vale do Paraíba e Litoral Norte 1991 a 2010.

\begin{tabular}{c|c|c|c|c}
\hline \multirow{2}{*}{ RMVPLN } & \multicolumn{2}{|c|}{ Absoluto } & \multicolumn{2}{c}{ Taxa Média Anual (\%) } \\
\cline { 2 - 5 } & $\mathbf{1 9 9 1 / 2 0 0 0}$ & $\mathbf{2 0 0 0 / 2 0 1 0}$ & $\mathbf{1 9 9 1 / 2 0 0 0}$ & $\mathbf{2 0 0 0 / 2 0 1 0}$ \\
\hline Crescimento populacional & 340.516 & 272.484 & 2,10 & 1,29 \\
\hline Crescimento Migratório & 111.222 & 65.690 & 0,68 & 0,31 \\
\hline $\begin{array}{c}\text { Peso Relativo } \\
\text { da Migração (\%) }\end{array}$ & - & - & 32,7 & 24,1 \\
\hline
\end{tabular}

Fonte - Censos demográficos do IBGE de 1991, 2000 e 2010. Elaboração própria.

\section{MOVIMENTOS PENDULARES NA REGIÃO METROPOLITANA DO VALE DO PARAÍBA E LITORAL NORTE}

Ao analisar a problemática que envolve o movimento pendular no Brasil, Jardim (2012) considera que "deslocamentos cotidianos funcionam como uma proxy dos movimentos da economia e da sociedade contemporâneas, responsáveis pela criação de novos espaços e dinâmicas social e territorial" (p.61). Os deslocamentos, segundo o autor, devem ser lidos considerando os processos econômicos emergentes no século XX e XXI, em que a mobilidade está "associada direta e indiretamente a um sistema de carências e de necessidades referidas ao cotidiano da população" (JARDIM, 2012, p. 64). Nesse sentido, para a formação de Regiões Metropolitanas os movimentos pendulares são um importante aspecto da dinâmica urbana contemporânea e tendem a ser mais intensos em áreas de maior concentração populacional. E ainda, "constituem uma dimensão da organização e da alocação das atividades econômicas, são mediatizados pela confluência dos processos de transformação do espaço urbano" (ÂNTICO, 2005, p. 110).

No Censo Demográfico de 2010, Delgado et al. (2016, p. 223) mencionam que " $12,8 \%$ da população brasileira de 10 anos ou mais de idade que se encontrava ocupada trabalhava fora do município de residência". Assim, tende-se a interpretar que os movimentos pendulares são importantes em contextos urbanos metropolitanos, estando vinculados à distribuição das funções urbanas em dado momento. $\mathrm{Na}$ RMVPLN é possível observar a seguinte configuração quanto aos movimentos pendulares, conforme mostram as Figuras 4 e 5, para 2000 e 2010. Nessa representação nota-se a intensificação dos movimentos pendulares em volume e direções na última década.

$\begin{array}{llllll}\text { Caminhos de Geografia } & \text { Uberlândia-MG } & \text { v. 21, n. 78 } & \text { Dez/2020 } & \text { p. 192-210 } & \text { Página } 199\end{array}$


Figura 4 - Movimentos pendulares na Região Metropolitana do Vale do Paraíba e Litoral Norte (2000).

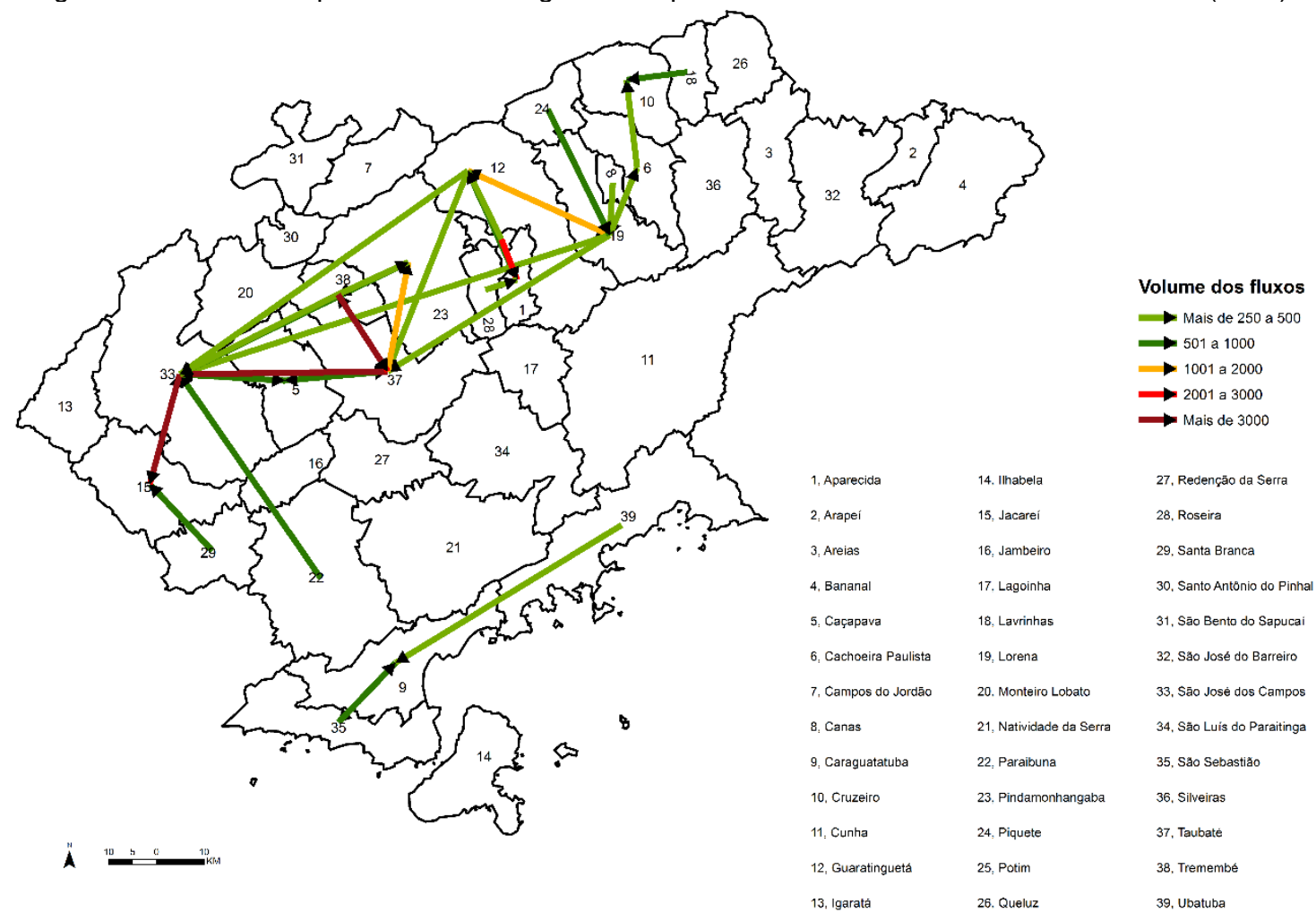

Fonte - Censos demográficos do IBGE de 2000 e 2010. Elaboração própria.

Figura 5 - Movimentos Pendulares na Região Metropolitana do Vale do Paraíba e Litoral Norte (2010).

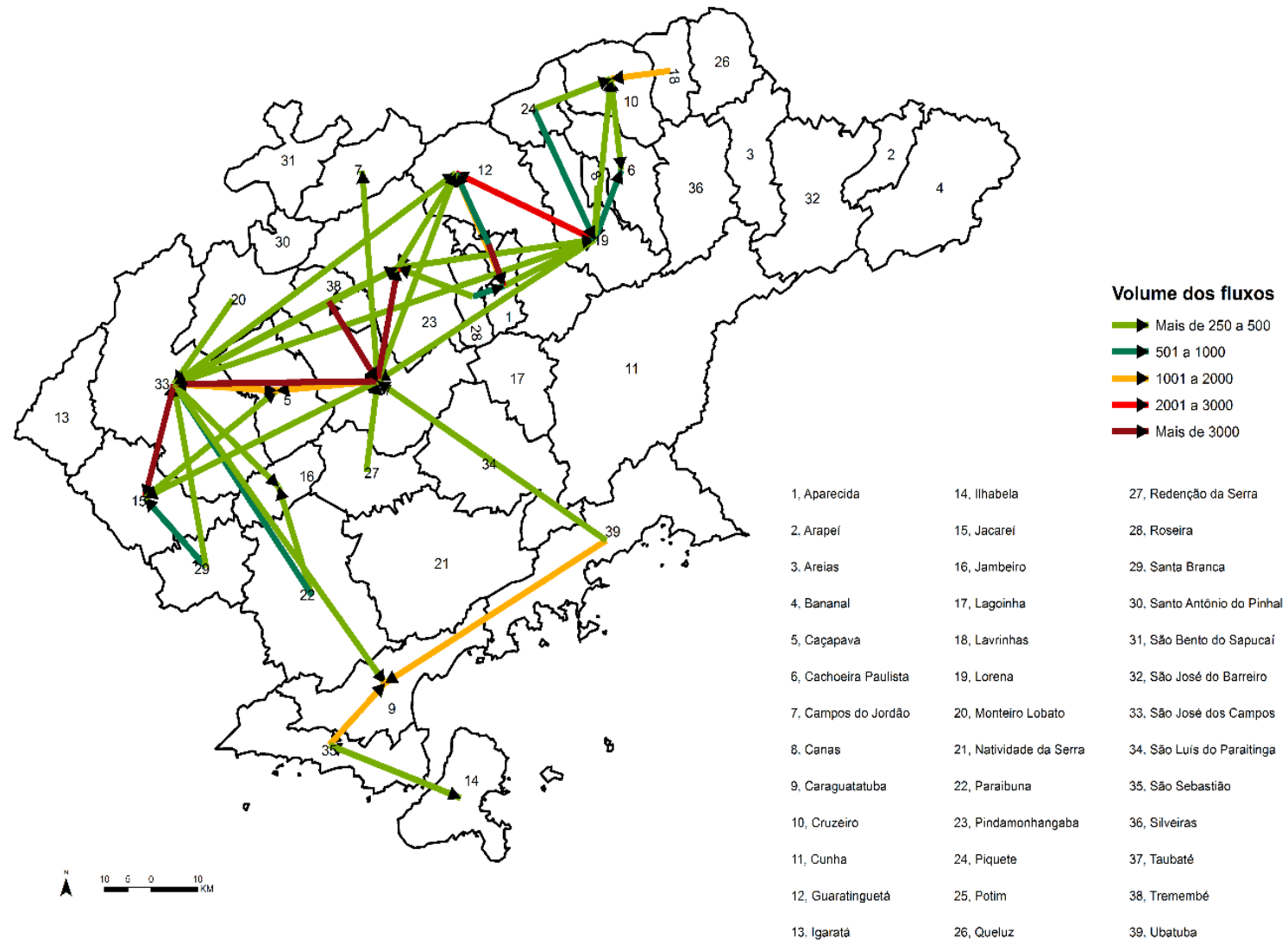

Fonte - Censos demográficos do IBGE de 2000 e 2010. Elaboração própria. 
Uma análise descritiva dos dados do Censo Demográfico 2000 indica que os principais movimentos pendulares na região, eram originados de Jacareí e tinham como direção São José dos Campos, com cerca de 8.573 deslocamentos. Tremembé e Taubaté apresentaram 5.528 deslocamentos diários e Pindamonhangaba e Taubaté cerca de 3.267 deslocamentos. As populações residentes dos municípios de Taubaté e Caçapava também se deslocavam em direção à São José dos Campos, demonstrando a centralidade do município na Região Metropolitana. No entanto, ainda é válido destacar que a população de São José dos Campos também se deslocava, especialmente para Jacareí, com cerca de 2.814 deslocamentos diários. Quando se considera os municípios menores como Potim que no ano de 2000 tinha uma população de 13.562 habitantes, cerca de 2.374 (cerca de $17 \%$ da população) se deslocavam para o município de Aparecida.

Já em 2010, o Censo Demográfico apontou que houve um aumento significativo nos movimentos entre as cidades supracitadas ${ }^{2}$. Esses movimentos cuja origem eram Jacareí em direção à São José dos Campos, alcançaram a cifra de 18.607. Assim, em ordem do volume de deslocamentos, temos: $1^{\circ}$ Jacareí para São José dos Campos (18.607); 2o Tremembé para Taubaté (6.647); $3^{\circ}$ Pindamonhangaba para Taubaté (6.913); 4ํ Potim para Aparecida (3.879); 5ํㅗ̃o José dos Campos para Jacareí (4.686); 6ํㅡ Caçapava para São José dos Campos (4.063); $7^{\circ}$ Taubaté para São José dos Campos (4.010).

As maiores trocas populacionais eram realizadas para trabalho (segundo os municípios de destino). Os números totais em 2000 são de 48.335 para trabalho e 10.260 para estudo. Em 2010 os números são de 112.547 para trabalho e 21.826 para estudo. A RMVPLN apresenta um significativo parque industrial e tecnológico, além de um dinâmico setor de comércio e serviços. Quando se avalia o mercado de trabalho formal da Região considerando os dados da Relação de Indicadores Sociais do Ministério do Trabalho e Emprego (RAIS - MTE, 2010).

Tabela 3 - Empregos Formais - Municípios concentradores do parque industrial da RMVPLN - 2000 -2010.

\begin{tabular}{lcc}
\hline MUNICÍPIO & $\mathbf{2 0 0 0}$ & $\mathbf{2 0 1 0}$ \\
CARAGUATATUBA & 8.455 & 21.132 \\
GUARATINGUETÁ & 18.052 & 24.886 \\
JACAREÍ & 30.049 & 41.594 \\
PINDAMONHANGABA & 16.659 & 29.053 \\
SÃO JOSÉ DOS CAMPOS & 116.615 & 206.524 \\
TAUBATÉ & 52.241 & 80.056 \\
\hline
\end{tabular}

Fonte - Relação Anual de Informações Sociais - RAIS, do Ministério do Trabalho e Emprego - MTE. Fundação SEADE.

Quanto ao perfil dos indivíduos que se movimentam, destaca-se um aumento significativo de movimentos pendulares de mulheres: em 2000 registrou-se 21.931 deslocamentos, e em 2010 foram 47.142 deslocamentos. No caso das diferenças por sexo em 2000, na questão do trabalho o deslocamento de homens é mais de duas vezes maior que o de mulheres, com razão de sexo de 271,1. Em 2010 há uma diminuição desse indicador, mas ainda assim com grande diferença, sendo de 218,5. Em relação aos estudos, em 2000 há mais mulheres se deslocando, com razão de sexo de 75,6, com os números ficando mais equilibrados em 2010, com 102,6. São José dos Campos, por exemplo, concentra importantes centros de ensino, como a Universidade Estadual Paulista (UNESP); Universidade Federal de São Paulo (UNIFESP); Instituto Nacional de Pesquisas Espaciais (INPE); Instituto Tecnológico Aeronáutico (ITA); e a Universidade do Vale do Paraíba (UNIVAP), o que coloca o município em situação privilegiada em relação ao quesito atração por "estudo".

\footnotetext{
${ }^{2}$ Neste ponto, faz-se necessário um esclarecimento. Para ser possível comparar os dados dos Censos de 2000 e 2010, neste último ano foram agregados em uma única categoria os movimentos pendulares para trabalho e para estudo, devido ao fato de que no ano 2000 esses dados foram captados separadamente. Ao proceder com tal junção, foi necessário eliminar a dupla contagem daqueles que realizaram o movimento pendular tanto para trabalho quanto para estudo.
}

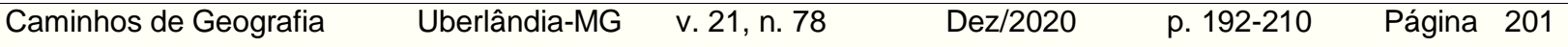


Em relação ao grau de instrução, verifica-se um aumento do número de movimentos pendulares de profissionais com ensino superior, de 9.305 em 2000 para 25.933 em 2010. Em estudo sobre os movimentos na Macrometrópole paulista, Cunha (2013, p. 449) considerava que esse fato merecia atenção, pois quando a RMVPLN era comparada com outra RM, verificava-se que cerca de $31,3 \%$ possuíam graduação ou pós-graduação, ou seja, esse tipo de movimentação era marca da particularidade da região, em que os movimentos pendulares de longa distância mais onerosos eram também presentes. Neste contexto, há de se considerar importantes seletividades sociodemográficas (BAENINGER, 2012).

Essas primeiras evidências empíricas revelam que a RMVPLN segue a tendência de outras regiões metropolitanas como a de São Paulo ou a de Campinas, em que há intenso movimento de população entre as cidades que compõem a região. Esses movimentos pendulares apontam para a problemática da estruturação dos municípios, das demandas por mercado de trabalho, serviços e equipamentos públicos. Assim, a mobilidade pendular pode revelar indícios de deficiência ou autossuficiência dos municípios que compõem a RMVPLN. Desse modo, considera-se, tal como Moura et al. (2005), que nos casos metropolitanos brasileiros os movimentos pendulares são objetivados pela condição de circulação de capital e "constituem importante referencial para a análise dos processos de metropolização e expansão urbana" (MOURA et al., 2005, p. 121).

\section{MOVIMENTOS PENDULARES NA RMVPLN EM 2010: ANÁLISE DESCRITIVA DE COMPLEMENTARIEDADES MULTIESCALARES A PARTIR DO LOCAL DE TRABALHO}

Os movimentos pendulares são fenômenos socioespaciais característico das regiões metropolitanas (JARDIM, 2012). De acordo com Farias (2018), tal evento estaria associado mais à dinâmica de produção e ocupação do espaço (divisão econômica e social do espaço) do que com à dinâmica demográfica propriamente dita. Os movimentos pendulares atendem anseios dos "indivíduos que desejam alcançar as oportunidades oferecidas pelo ambiente metropolitano" (FARIAS, 2018, p. 135) e/ou fora dele. Conforme citam Ojima e Marandola Jr. (2012) "desde o ano 2000 os municípios com maior proporção de deslocamentos pendulares estão localizados fora de regiões metropolitanas" (p.106). Logo tanto em áreas metropolitanas e outras, a saída permite acessar, fundamentalmente, o mercado de trabalho, comércio e serviços e integram as possibilidades das famílias e/ou indivíduos (OJIMA; MARANDOLA JR, 2012).

Desse modo, a ampliação dos espaços de vida (COURGEAU, 1988) numa escala local e regional incluem a migração, enquanto mudança definitiva de residência, e os movimentos pendulares que ocorrem cotidianamente. Esses dois fatos demográficos reorganizam os modos de uso e consumo dos espaços (OJIMA et al., 2015) e afetam diretamente as condições de vida da população. Desse modo, para atender a urbanização reflexiva "o sentido da cidade é exatamente a sua capacidade de ser espaço de mobilidade e fluxo" (MARANDOLA JR; OJIMA, 2014, p. 200), ou a "capacidade de sair dela, de não estar preso a ela, e poder trafegar entre elas, sem a nenhuma se fixar: impermanência" (OJIMA; MARANDOL JR, 2012, p.113). O direito demandado será pela mobilidade e mitigação dos riscos e vulnerabilidades emergentes do processo de mobilidade.

Considerando as reflexões dos parágrafos anteriores, e com a finalidade de aprofundar o debate para o objeto de estudo selecionado, ou seja, a conexão entre migração e movimentos pendulares na RMVPLN, se apresenta pertinente 0 cruzamento de diferentes modalidades migratórias (intrametropolitana, intramacrometropolitana, intraestadual e interestadual) com o local de trabalho da população. Esse aspecto indica as complementaridades entre os fenômenos da mobilidade residencial metropolitana e dos movimentos pendulares por razão de trabalho, juntamente com o processo de produção do espaço na RMVPLN. As Tabelas 4 e 5 apresentam dados sobre essas questões suscitadas.

A relevância das Tabelas 4 e 5 reside no fato de que elas retratam como ocorre o processo de periferização da ocupação metropolitana, mostrando que esse fenômeno não é acompanhado, necessariamente, pela desconcentração das atividades econômicas e pelo mercado de trabalho. $\mathrm{Na}$ maioria dos casos, morar perto do trabalho representa um custo elevado. Por conta disso, o indivíduo migra para outro município onde a habitação é mais barata e continua trabalhando no município de 
origem da migração. Deste fenômeno derivou-se as chamadas "cidades dormitórios" (OJIMA et al., 2010). Assim:

Com um mercado de trabalho mais flexível e incerto, mudanças permanentes de residência ampliam a insegurança, portanto, manter-se no seu porto seguro e deslocar-se diariamente para trabalhar em outras localidades/municípios parece se tornar o melhor mecanismo de adaptação (OJIMA et al., 2015, p. 138).

$\mathrm{Na}$ Tabela 4 se observa que quando considerados os municípios de residência e os municípios de trabalho dos migrantes, excetuando Arapeí e Cunha, o mercado de trabalho indicava trabalhadores migrantes e pendulares em todos os outros 37 municípios da Região.

Tabela 4 - Responsáveis pelos domicílios, migrantes de "data-fixa", por local de residência, segundo modalidade e local de trabalho - Intrametropolitana e intramacrometropolitano3. RMVPLN- 2005-2010.

\section{Modalidade migratória}

Intrametropolitano

Município de trabalho

Próprio Município Outro Outro município da RM

\section{Intramacrometropolitano}

\section{Município de trabalho}

Próprio Municíp Outro Outr

municíp io em municí o To muni Total

io 2005 RM cípio

\begin{tabular}{ccccccccccc} 
APARECIDA & 76,81 & 10,78 & 5,51 & 6,91 & 562 & 100,00 & 0,00 & 0,00 & 0,00 & 11 \\
ARAPEÍ & 96,74 & 3,26 & 0,00 & 0,00 & 66 & 0,00 & 0,00 & 0,00 & 0,00 & 0,00 \\
AREIAS & 78,10 & 9,49 & 4,88 & 7,53 & 90 & 0,00 & 0,00 & 0,00 & 0,00 & 0 \\
BANANAL & 56,70 & 8,23 & 8,50 & 26,57 & 58 & 0,00 & 0,00 & 0,00 & 0,00 & 0 \\
CAÇAPAVA & 70,22 & 13,83 & 11,52 & 4,43 & 1505 & 66,54 & 0,00 & 33,46 & 0,00 & 59 \\
$\begin{array}{c}\text { CACHOEIRA } \\
\text { PAULISTA }\end{array}$ & 76,19 & 10,26 & 5,46 & 8,09 & 610 & 100,00 & 0,00 & 0,00 & 0,00 & 45 \\
$\begin{array}{c}\text { CAMPOS DO } \\
\text { JORDÃO }\end{array}$ & 94,20 & 1,79 & 2,13 & 1,87 & 490 & 100,00 & 0,00 & 0,00 & 0,00 & 47 \\
CANAS & 43,05 & 32,32 & 15,19 & 9,44 & 219 & 0,00 & 0,00 & 0,00 & 0,00 & 0 \\
CARAGUATATUBA & 84,67 & 9,26 & 4,84 & 1,24 & 3593 & 86,91 & 3,85 & 5,85 & 3,39 & 294 \\
CRUZEIRO & 95,78 & 0,00 & 4,22 & 0,00 & 555 & 100,00 & 0,00 & 0,00 & 0,00 & 8 \\
CUNHA & 95,43 & 4,57 & 0,00 & 0,00 & 381 & 0,00 & 0,00 & 0,00 & 0,00 & 0 \\
GUARATINGUETÁ & 74,96 & 11,43 & 9,61 & 4,00 & 1902 & 100,00 & 0,00 & 0,00 & 0,00 & 10 \\
IGARATÁ & 67,64 & 8,52 & 9,10 & 14,73 & 291 & 73,72 & 26,28 & 0,00 & 0,00 & 10 \\
ILHABELA & 87,17 & 2,56 & 5,07 & 5,20 & 785 & 85,88 & 14,12 & 0,00 & 0,00 & 71 \\
\hline
\end{tabular}

\footnotetext{
${ }^{3}$ Esclarece-se que os movimentos intrametropolitanos são aqueles que ocorrem entre os municípios da Região Metropolitana. Já os intramacrometropolitano são aqueles que acontecem entre os municípios da macrometrópole. No caso paulista, pode-se citar os movimentos populacionais derivados dos municípios que compõem as Regiões Metropolitanas de São Paulo, da Baixada Santista, de Campinas e do Vale do Paraíba e Litoral Norte (EMPLASA, 2014).

${ }^{4}$ O Censo brasileiro inclui, desde 1991, os quesitos tempo de residência no local de moradia atual e lugar de última residência. Além destas, há também a variável sobre o local de residência em uma data fixa cinco anos antes do recenseamento (RIGOTTI, 2010).
} 


\begin{tabular}{|c|c|c|c|c|c|c|c|c|c|c|}
\hline JACAREÍ & 47,94 & 33,70 & 11,50 & 6,86 & 3794 & 61,16 & 0,00 & 8,52 & 30,32 & 108 \\
\hline JAMBEIRO & 73,00 & 17,78 & 7,77 & 1,45 & 356 & 100,00 & 0,00 & 0,00 & 0,00 & 4 \\
\hline LAGOINHA & 82,57 & 10,28 & 3,80 & 3,35 & 187 & 0,00 & 0,00 & 0,00 & 0,00 & 0 \\
\hline LAVRINHAS & 26,69 & 52,97 & 16,33 & 4,01 & 259 & 0,00 & 0,00 & 0,00 & 0,00 & 0 \\
\hline LORENA & 65,94 & 18,59 & 10,08 & 5,39 & 1383 & 100,00 & 0,00 & 0,00 & 0,00 & 21 \\
\hline $\begin{array}{l}\text { MONTEIRO } \\
\text { LOBATO }\end{array}$ & 76,24 & 8,81 & 11,83 & 3,12 & 204 & 100,00 & 0,00 & 0,00 & 0,00 & 6 \\
\hline $\begin{array}{l}\text { NATIVIDADE DA } \\
\text { SERRA }\end{array}$ & 83,94 & 12,66 & 3,40 & 0,00 & 281 & 44,72 & 0,00 & 55,28 & 0,00 & 7 \\
\hline PARAIBUNA & 81,19 & 14,22 & 3,05 & 1,54 & 352 & 0,00 & 0,00 & 0,00 & $\begin{array}{c}100,0 \\
0\end{array}$ & 5 \\
\hline $\begin{array}{c}\text { PINDAMONHANGA } \\
\text { BA }\end{array}$ & 70,03 & 14,57 & 11,34 & 4,06 & 3168 & 62,35 & 6,76 & 30,89 & 0,00 & 149 \\
\hline PIQUETE & 55,46 & 18,10 & 20,40 & 6,04 & 243 & 0,00 & 0,00 & 0,00 & 0,00 & 0 \\
\hline РОTIM & 34,37 & 36,67 & 24,58 & 4,39 & 1071 & 0,00 & 0,00 & 0,00 & 0,00 & 0 \\
\hline QUELUZ & 91,18 & 0,00 & 3,94 & 4,87 & 129 & 0,00 & 0,00 & 0,00 & $\begin{array}{c}100,0 \\
0\end{array}$ & 4 \\
\hline $\begin{array}{l}\text { REDENÇÃO DA } \\
\text { SERRA }\end{array}$ & 71,78 & 17,72 & 8,61 & 1,89 & 183 & 0,00 & 0,00 & 0,00 & 0,00 & 0 \\
\hline ROSEIRA & 51,79 & 18,48 & 23,74 & 5,99 & 499 & 0,00 & 0,00 & 100,00 & 0,00 & 3 \\
\hline SANTA BRANCA & 52,78 & 23,37 & 11,90 & 11,95 & 453 & 0,00 & 0,00 & 0,00 & $\begin{array}{c}100,0 \\
0\end{array}$ & 4 \\
\hline $\begin{array}{c}\text { SANTO ANTÔNIO } \\
\text { DO PINHAL }\end{array}$ & 71,06 & 21,67 & 7,27 & 0,00 & 207 & 0,00 & 0,00 & 0,00 & 0,00 & 0 \\
\hline $\begin{array}{l}\text { SÃO BENTO DO } \\
\text { SAPUCAÍ }\end{array}$ & 86,23 & 9,00 & 4,77 & 0,00 & 235 & 100,00 & 0,00 & 0,00 & 0,00 & 12 \\
\hline $\begin{array}{l}\text { SÃO JOSÉ DO } \\
\text { BARREIRO }\end{array}$ & 87,35 & 0,00 & 10,45 & 2,19 & 81 & 0,00 & 0,00 & 0,00 & 0,00 & 0 \\
\hline $\begin{array}{l}\text { SÃO JOSÉ DOS } \\
\text { CAMPOS }\end{array}$ & 84,93 & 7,51 & 2,97 & 4,59 & 9251 & 93,86 & 0,00 & 4,04 & 2,11 & 1121 \\
\hline $\begin{array}{l}\text { SÃO LUÍS DO } \\
\text { PARAITINGA }\end{array}$ & 87,36 & 2,57 & 3,44 & 6,62 & 299 & 0,00 & 0,00 & 0,00 & 0,00 & 0,00 \\
\hline SÃO SEBASTIÃO & 86,56 & 5,60 & 5,32 & 2,52 & 1612 & 92,21 & 0,00 & 0,00 & 7,79 & 132 \\
\hline SILVEIRAS & 70,83 & 7,83 & 19,05 & 2,29 & 153 & 66,30 & 0,00 & 33,70 & 0,00 & 7 \\
\hline TAUBATÉ & 82,43 & 8,35 & 7,16 & 2,05 & 5676 & 86,18 & 3,38 & 4,01 & 6,43 & 283 \\
\hline TREMEMBÉ & 31,99 & 44,60 & 20,94 & 2,47 & 2016 & 0,00 & 0,00 & 0,00 & 0,00 & 0 \\
\hline UBATUBA & 87,38 & 2,28 & 3,93 & 6,41 & 1488 & 73,60 & 13,97 & 0,00 & 12,43 & 90 \\
\hline RMVPLN & 73,73 & 14,11 & 8,10 & 4,06 & 44691 & 86,78 & 2,24 & 6,28 & 4,70 & 2509 \\
\hline
\end{tabular}

Fonte - IBGE (Microdados da amostra dos Censos Demográficos 2000 e 2010). Tabulações especiais dos autores.

Os resultados descritos na Tabela 4 para a modalidade intrametropolitana mostram que, em 2010, quase $74 \%$ dos migrantes responsáveis pelos domicílios que residiam na RMVPLN trabalhavam no próprio município de residência, sugerindo que o deslocamento foi influenciado pela dinâmica do mercado de trabalho. Ou seja, pode-se supor que, nestes casos, o indivíduo tenha migrado para residir 
próximo ao local de trabalho. Também se destaca que $14 \%$ dos migrantes responsáveis pelos domicílios continuaram trabalhando no município de residência anterior. Nesse sentido, seria possível dizer que a mobilidade residencial possui como condicionante mais significativo a dinâmica do mercado imobiliário dos municípios, considerando que residir próximo ao local de trabalho não se mostra um fator preponderante, especialmente por conta do alto preço do solo nos municípios que concentram as atividades econômicas. Essa hipótese é reforçada no caso do Vale do Paraíba, devido principalmente à concentração de tais atividades e dos empregos formais em municípios específicos da região, como São José dos Campos, Taubaté e Jacareí, como mostra a Tabela 2.

Tabela 5 - Responsáveis pelos domicílios, migrantes de "data-fixa", por local de residência, segundo modalidade e local de trabalho - Intraestadual e Interestadual. RMVPLN-2005-2010.

\begin{tabular}{|c|c|c|c|c|c|c|c|c|c|c|}
\hline \multirow{4}{*}{$\begin{array}{l}\text { Município de } \\
\text { residência em } \\
2010\end{array}$} & \multicolumn{10}{|l|}{$\begin{array}{l}\text { Modalidade } \\
\text { migratória }\end{array}$} \\
\hline & \multicolumn{5}{|c|}{ Intraestadual } & \multicolumn{5}{|c|}{ Interestadual } \\
\hline & \multicolumn{5}{|c|}{ Município de trabalho } & \multicolumn{5}{|c|}{ Município de trabalho } \\
\hline & $\begin{array}{l}\text { Próprio } \\
\text { município }\end{array}$ & $\begin{array}{c}\text { Muni } \\
\text { cípio } \\
\text { em } \\
2005\end{array}$ & $\begin{array}{c}\text { Outro } \\
\text { municí } \\
\text { pio da } \\
\text { RM }\end{array}$ & $\begin{array}{l}\text { Outro } \\
\text { municí } \\
\text { pio }\end{array}$ & $\begin{array}{l}\text { Tot } \\
\text { al }\end{array}$ & $\begin{array}{c}\text { Próprio } \\
\text { municí } \\
\text { pio }\end{array}$ & $\begin{array}{l}\text { Municí } \\
\text { pio em } \\
2005\end{array}$ & $\begin{array}{c}\text { Outro } \\
\text { municí } \\
\text { pio da } \\
\text { RM }\end{array}$ & $\begin{array}{c}\text { Outro } \\
\text { municí } \\
\text { pio }\end{array}$ & Total \\
\hline APARECIDA & 100,00 & 0,00 & 0,00 & 0,00 & 95 & 82,84 & 0,00 & 17,16 & 0,00 & 201 \\
\hline ARAPEÍ & 0,00 & 0,00 & 0,00 & 0,00 & 0 & 72,99 & 27,01 & 0,00 & 0,00 & 53 \\
\hline AREIAS & 0,00 & 0,00 & 0,00 & 100,00 & 2 & 28,20 & 0,00 & 59,94 & 11,86 & 13 \\
\hline BANANAL & 100,00 & 0,00 & 0,00 & 0,00 & 5 & 64,39 & 15,30 & 11,37 & 8,94 & 96 \\
\hline CAÇAPAVA & 71,38 & 0,00 & 28,62 & 0,00 & 100 & 87,40 & 0,00 & 7,46 & 5,14 & 583 \\
\hline $\begin{array}{l}\text { CACHOEIRA } \\
\text { PAULISTA }\end{array}$ & 100,00 & 0,00 & 0,00 & 0,00 & 22 & 84,47 & 0,00 & 8,76 & 6,76 & 345 \\
\hline $\begin{array}{l}\text { CAMPOS DO } \\
\text { JORDÃO }\end{array}$ & 100,00 & 0,00 & 0,00 & 0,00 & 55 & 100,00 & 0,00 & 0,00 & 0,00 & 380 \\
\hline CANAS & 0,00 & $\begin{array}{l}100 \\
00\end{array}$ & 0,00 & 0,00 & 3 & 55,64 & 0,00 & 22,41 & 21,95 & 44 \\
\hline $\begin{array}{l}\text { CARAGUATATU } \\
\text { BA }\end{array}$ & 93,15 & 0,00 & 1,86 & 5,00 & 517 & 92,70 & 0,40 & 5,28 & 1,61 & 2375 \\
\hline CRUZEIRO & 73,82 & 0,00 & 26,18 & 0,00 & 32 & 88,24 & 0,00 & 4,12 & 7,63 & 514 \\
\hline CUNHA & 100,00 & 0,00 & 0,00 & 0,00 & 23 & 40,00 & 0,00 & 60,00 & 0,00 & 17 \\
\hline $\begin{array}{l}\text { GUARATINGUE } \\
\text { TÁ }\end{array}$ & 68,26 & 8,13 & 23,61 & 0,00 & 135 & 81,92 & 3,32 & 8,48 & 6,29 & 844 \\
\hline IGARATÁ & 100,00 & 0,00 & 0,00 & 0,00 & 15 & 62,01 & 0,00 & 3,80 & 34,20 & 97 \\
\hline ILHABELA & 75,33 & 0,00 & 12,52 & 12,15 & 81 & 96,15 & 0,00 & 3,85 & 0,00 & 1031 \\
\hline JACAREÍ & 85,45 & 0,00 & 11,15 & 3,40 & 340 & 67,39 & 1,38 & 22,66 & 8,57 & 1526 \\
\hline JAMBEIRO & 100,00 & 0,00 & 0,00 & 0,00 & 15 & 100,00 & 0,00 & 0,00 & 0,00 & 80 \\
\hline LAGOINHA & 100,00 & 0,00 & 0,00 & 0,00 & 5 & 100,00 & 0,00 & 0,00 & 0,00 & 13 \\
\hline LAVRINHAS & 74,94 & 0,00 & 25,06 & 0,00 & 9 & 42,81 & 0,00 & 57,19 & 0,00 & 34 \\
\hline LORENA & 85,65 & 0,00 & 14,35 & 0,00 & 28 & 74,61 & 0,00 & 15,63 & 9,76 & 321 \\
\hline $\begin{array}{l}\text { MONTEIRO } \\
\text { LOBATO }\end{array}$ & 100,00 & 0,00 & 0,00 & 0,00 & 13 & 100,00 & 0,00 & 0,00 & 0,00 & 39 \\
\hline $\begin{array}{l}\text { NATIVIDADE DA } \\
\text { SERRA }\end{array}$ & 100,00 & 0,00 & 0,00 & 0,00 & 7 & 87,35 & 0,00 & 12,65 & 0,00 & 20 \\
\hline PARAIBUNA & 60,60 & 0,00 & 39,40 & 0,00 & 28 & 92,31 & 0,00 & 7,69 & 0,00 & 80 \\
\hline
\end{tabular}




\begin{tabular}{|c|c|c|c|c|c|c|c|c|c|c|}
\hline $\begin{array}{l}\text { PINDAMONHAN } \\
\text { GABA }\end{array}$ & 79,53 & 0,00 & 15,20 & 5,27 & 204 & 81,96 & 1,42 & 15,20 & 1,43 & 1027 \\
\hline PIQUETE & 100,00 & 0,00 & 0,00 & 0,00 & 11 & 68,51 & 0,00 & 31,49 & 0,00 & 60 \\
\hline РОTIM & 91,53 & 0,00 & 8,47 & 0,00 & 123 & 37,74 & 0,00 & 62,26 & 0,00 & 121 \\
\hline QUELUZ & 100,00 & 0,00 & 0,00 & 0,00 & 6 & 90,45 & 2,18 & 0,00 & 7,37 & 188 \\
\hline $\begin{array}{l}\text { REDENÇÃO DA } \\
\text { SERRA }\end{array}$ & 0 & 0 & 0 & 0 & 0 & 100,00 & 0,00 & 0,00 & 0,00 & 15 \\
\hline ROSEIRA & 45,56 & 0,00 & 54,44 & 0,00 & 28 & 70,59 & 0,00 & 11,96 & 17,45 & 56 \\
\hline $\begin{array}{l}\text { SANTA } \\
\text { BRANCA }\end{array}$ & 65,33 & 0,00 & 34,67 & 0,00 & 24 & 70,84 & 0,00 & 0,00 & 29,16 & 73 \\
\hline $\begin{array}{l}\text { SANTO } \\
\text { ANTÔNIO DO } \\
\text { PINHAL }\end{array}$ & 100,00 & 0,00 & 0,00 & 0,00 & 3 & 89,75 & 0,00 & 10,25 & 0,00 & 31 \\
\hline $\begin{array}{l}\text { SÃO BENTO DO } \\
\text { SAPUCAÍ }\end{array}$ & 28,10 & $\begin{array}{c}61,2 \\
0\end{array}$ & 0,00 & 10,70 & 60 & 81,66 & 4,09 & 5,06 & 9,20 & 144 \\
\hline $\begin{array}{l}\text { SÃO JOSÉ DO } \\
\text { BARREIRO }\end{array}$ & 100,00 & 0,00 & 0,00 & 0,00 & 6 & 94,94 & 5,06 & 0,00 & 0,00 & 59 \\
\hline $\begin{array}{l}\text { SÃO JOSÉ DOS } \\
\text { CAMPOS }\end{array}$ & 87,34 & 0,90 & 4,38 & 7,39 & $\begin{array}{c}165 \\
6\end{array}$ & 92,61 & 0,37 & 3,03 & 3,99 & $\begin{array}{c}1252 \\
8\end{array}$ \\
\hline $\begin{array}{l}\text { SÃO LUÍS DO } \\
\text { PARAITINGA }\end{array}$ & 0,00 & 0,00 & 0,00 & 0,00 & 0 & 100,00 & 0,00 & 0,00 & 0,00 & 12 \\
\hline $\begin{array}{l}\text { SÃO } \\
\text { SEBASTIÃO }\end{array}$ & 90,32 & 2,45 & 0,64 & 6,59 & 453 & 95,68 & 0,00 & 2,95 & 1,37 & 2170 \\
\hline SILVEIRAS & 0,00 & 0,00 & 0,00 & 0,00 & 0 & 56,92 & 7,38 & 8,99 & 26,71 & 35 \\
\hline TAUBATÉ & 82,64 & 0,00 & 10,31 & 7,05 & 580 & 87,90 & 0,66 & 7,35 & 4,09 & 2919 \\
\hline TREMEMBÉ & 100,00 & 0,00 & 0,00 & 0,00 & 38 & 49,52 & 0,00 & 45,87 & 4,60 & 262 \\
\hline UBATUBA & 100,00 & 0,00 & 0,00 & 0,00 & 313 & 91,74 & 0,91 & 3,24 & 4,11 & 1002 \\
\hline RMVPLN & 86,49 & 1,53 & 6,82 & 5,15 & $\begin{array}{c}503 \\
3\end{array}$ & 88,81 & 0,65 & 6,51 & 4,03 & $\begin{array}{c}2940 \\
6\end{array}$ \\
\hline
\end{tabular}

Fonte - IBGE (Microdados da amostra dos Censos Demográficos 2000 e 2010). Tabulações especiais dos autores.

Devido à dinâmica do mercado imobiliário, morar próximo ao local de trabalho tem custos econômicos elevados, fazendo com que o indivíduo migre para outro município onde a habitação é mais barata e continue trabalhando no município de origem da migração. No entanto, no caso de São José dos Campos, quem migra para trabalhar neste local (município polo regional de empregos), acaba por morar no próprio município (84,93\%). Já no caso de Jacareí, observa-se que há um movimento grande originado de São José dos Campos tendo como resultado que os valores para a migração e para o próprio município em 2005 são bem mais próximos (47\% e 33,7\%). Fenômeno parecido ocorre no caso de Taubaté e Tremembé, onde observa-se que as pessoas continuam residindo nesta enquanto trabalham naquela.

Quando observada a modalidade intramacrometropolitana - Tabela 4 -, alguns casos chamam a atenção. O primeiro é que muitas pessoas trabalham em outras metrópoles e residem nos municípios da RMVPLN. São Paulo e Campinas estariam na área de influência, e supostamente, por serem polos produtivos, atraem trabalhadores da região. O segundo é que para a residência em 2005 , observa-se que esta é maior nos municípios turísticos como llhabela, Ubatuba e Igaratá, mostrando a ligação de tais lugares com outros municípios de regiões que compõem a Macrometrópole Paulista ${ }^{5}$.

\footnotetext{
${ }^{5}$ A Macrometrópole Paulista (MMP) é composta pela Região Metropolitana de São Paulo (RMSP), juntamente com as RMs da Baixada Santista, de Campinas, de Sorocaba e do Vale do Paraíba e Litoral Norte, as Aglomerações Urbanas de Jundiaí e de Piracicaba e a Unidade Regional Bragantina, ainda não institucionalizada.
} 
Outro ponto importante presente nos dados apresentados - Tabela 5 - é que os movimentos pendulares retraem conforme aumentam as distâncias. Isso fica claro na modalidade intraestadual e interestadual, em que tais movimentos diminuem sua incidência. Ainda assim, pode-se destacar alguns casos como Bananal e Arapeí que, por conta da proximidade com o estado do Rio de Janeiro, é possível inferir que estabelecem maiores movimentos pendulares com essa localidade do que com outros municípios no estado de que fazem parte.

\section{CONSIDERAÇÕES FINAIS}

O artigo procurou discorrer sobre as relações entre a questão da integração regional e os movimentos pendulares, no contexto socioespacial da RMVPLN. Buscou-se ressaltar que tais relações se dão por meio de fluxos econômicos de natureza diversa. Os movimentos pendulares representam uma expressão espacial das dinâmicas de transformação e funcionamento das estruturas socioeconômicas e urbanas. Configurando os movimentos de população de um ponto a outro do espaço, os movimentos pendulares terminam por indicar as situações de defasagem, desequilíbrio e desigualdade da rede urbana regional.

Os movimentos pendulares podem ser analisados como fenômeno de conexão entre as cidades, tomadas pelos locais de residência e os locais destinados ao trabalho e estudo (MARANDOLA JR; OJIMA, 2014), subentendendo a incorporação de parcelas populacionais nas estruturas de atividades e empregos das cidades que mais atraem tais movimentos, e de outro lado, as estruturas deficitárias que criam a dependência das cidades que mais deflagram os deslocamentos de saída. Daí a acepção primordial da integração regional que os movimentos pendulares de trabalhadores e estudantes materializam, conformando a regionalização do cotidiano (REIS FILHO, 2006; CUNHA et al., 2013). Do cotidiano do trabalho e estudo, mas também daquele ligado ao consumo e aos serviços, ao lazer, inclusive, com frequências de deslocamentos não necessariamente diárias.

Se os movimentos pendulares conformam essa integração funcional pelas interdependências entre os municípios ou cidades, eles só se concretizam, de fato, porque existem condições gerais para outras formas de integração, que coexistem, e das quais não se dissociam de sua realidade e de seu valor de análise. Sem o sistema viário e os meios de deslocamento terrestre dados pelos serviços de transporte intermunicipal ou interurbano, os movimentos pendulares não se sustentariam nem poderiam se intensificar, em período recente da história, de uma década para outra. Sem as condições de acessibilidade social dada pelo acesso à informação e a renda, a decisão de se deslocar não se efetiva. Sem os meios de integração simbólica, política e normativa, tampouco os movimentos pendulares seriam engendrados como opção para acesso a oportunidades de trabalho e estudo.

Tais fatores expressam claramente a relação entre movimentos pendulares, integração regional e globalização, uma vez que sem os suportes de integração territorial (rodovias e transportes terrestres), sem as facilidades e velocidade no acesso a informações e nos processos de comunicação social (condição essencial à globalização), sem os desígnios políticos e investimentos direcionados à dinamização econômico-produtiva, os movimentos pendulares não seriam desencadeados e não teriam se intensificado, integrando municípios e regiões.

Por isso, a integração regional deve ser, de fato, inserida no contexto de estudo de processos históricos amplos, como o da globalização, que se instrumentaliza pela organização e dinâmicas do espaço metropolitano e regional e, também, pela própria criação de regiões metropolitanas. Esta que, para além da definição técnica de critérios de regionalização (criação de regiões), se sustenta por um projeto político estadual inclinado ao favorecimento de lógicas hegemônicas de produção social do espaço, vale dizer, constituindo uma forma de obtenção de aportes financeiros federais e uma "solução para viabilizar um capital que [ganha] uma enorme dimensão e [necessita] prevalecer-se de regulamentações específicas, além da criação de espaços exclusivos para certas atividades" (SANTOS, 1994, p. 137). Ao promover irradiação ideológica (SANTOS, 1993), projetos políticos e aparatos normativos, tais processos de integração regional realimentam as tendências de reprodução econômico-produtiva e dos modos de viver e habitar a partir das metrópoles e regiões metropolitanas, em novos alcances geográficos, gerando e/ou acirrando desigualdades sociais e econômicas, e estabelecendo as assimetrias entre espaços hegemônicos e hegemonizados.

$\mathrm{Na}$ condição de tendência demográfica integrada às estruturas da divisão social do trabalho e de serviços educacionais - dentre outros serviços que oferecem as diferentes cidades da rede urbana regional, polarizada pelas metrópoles e grandes centros regionais próximos -, os movimentos

$\begin{array}{llllll}\text { Caminhos de Geografia } & \text { Uberlândia-MG } & \text { v. 21, n. 78 } & \text { Dez/2020 } & \text { p. 192-210 } & \text { Página } 207\end{array}$


pendulares subentendem, igualmente, as demandas não atendidas em contextos de estruturas socioeconômicas e urbanas sem vantagens comparativas ou mais deficitárias, ou mesmo, as estratégias de sobrevivência envolvendo as opções mais propícias no processo de decisão pelos locais de residência ou trabalho.

$\mathrm{Na}$ perspectiva de um planejamento socialmente necessário e construído, questões urbanas e regionais emergentes, tais como a que considera as formas objetivas de realização do princípio de integração (hoje vigente nos processos de resgate da política territorial de âmbito regional), devem ser melhor explicitadas e cotejadas aos entendimentos do que constitui, de fato, os interesses comuns. As opções de permanência ou deslocamento para trabalho ou estudo, ou mesmo, para o consumo ou o benefício de serviços diversos, devem ser ambas consideradas e as provisões ofertadas para atendêlas.

No cerne dessa busca, a integração regional supõe, essencialmente, a acepção de ação política, de ações integradas em vista de análises e fóruns de discussão; dinamização de relações sociais e interinstitucionais; o diálogo entre saberes, mobilizações e criação de forças de resistência a partir dos mais diferentes lugares, enfim.

\section{REFERÊNCIAS}

ALVES, José Eustáquio Diniz. A transição demográfica e a janela de oportunidade. São Paulo. Instituo de Economia Internacional. Fernand Braudel. 2008.

ANDRADE, D. J. A Rodovia Presidente Dutra como elemento estruturador e a desarticulação da urbanização do Vale do Paraíba. Tese de Doutorado em Planejamento Urbano e Regional. Programa de Pós-Graduação em Planejamento Urbano e Regional, Universidade do Vale do Paraíba, 2019.

ASCHER, F. Metápolis ou l'avenir dês villes. Paris: Odile Jacob, 1995.

BAENINGER, R. Migrações internas no Brasil século 21: evidências empíricas e desafios conceituais. In: CUNHA, J. P (Org). Mobilidade espacial da população: desafios teóricos e metodológicos para o seu estudo. Campinas: Núcleo de Estudos de População - Nepo/Unicamp, 2011.

BAENINGER, R. Fases e faces da migração em São Paulo. Campinas: Núcleo de Estudos de População - Nepo/Unicamp, 2012.

BRASIL. Lei no 13.089, de 12 de janeiro de 2015. Institui o Estatuto da Metrópole. Disponível em: http://http://www.planalto.gov.br/ccivil_03/_ato2015-2018/2015/lei/l13089.htm. Acesso: 20 de fev. 2020.

BESSA, K. Estudos sobre a rede urbana: os precursores da teoria das localidades centrais. In: GeoTextos, v. 8, n. 1, jul. 2012. https://doi.org/10.9771/1984-5537geo.v8i1.6222

COURGEAU, D. Méthodes de Mesure de la Mobilité Spatiale: Migrations internes, mobilité temporaire, navettes. Paris: Éditions de L'Institut National d'Études Démographiques. 1988. https://doi.org/10.2307/1533496

CASTELLS, M. A sociedade em rede. São Paulo, Paz e Terra, 1999.

CLEMENTINO, M. L.; PESSOA, Z. Natal, uma metrópole em formação. São Paulo, EDUC, 2009.

CUNHA, J. M. P. A mobilidade pendular na Macrometrópole Paulista: diferenciação e complementaridade socioespacial. In: Cad. Metrop., São Paulo, v. 15, n. 30, pp. 433-459, dez 2013. https://doi.org/10.1590/2236-9996.2013-3004 
Dinâmica demográfica e migratória 1991-2010: realidades e mitos. In: MARQUES, E. (Org.) A metrópole de São Paulo no século XXI - Espaços, heterogeneidades e desigualdades. São Paulo: Editora UNESP, 2015a.

Mobilidade populacional e expansão urbana: o caso da Região Metropolitana de São Paulo. 1. ed. Campinas: Librum, 2015b.

; SILVA, K. A. A; BECCENERI, L. B. Vale do Paraíba e Litoral Norte: diversidades socioespaciais. Editora Librum. Campinas, 2019.

EMPLASA. PAM - Plano de Ação da Macrometrópole Paulista 2013-2040: política de desenvolvimento da macrometrópole (4 volumes). São Paulo, Emplasa, 2014.

FARIAS, L. A. C. Mobilidade populacional e produção do espaço urbano na Baixada Santista: um olhar sociodemográfico sobre sua trajetória nos últimos 20 anos. Tese (doutorado) - Universidade Estadual de Campinas, Instituto de Filosofia e Ciências Humanas. - Campinas, SP: (s.n.), 2018.

IBGE. Instituto Brasileiro de Geografia e Estatística. Censo demográfico de 2000. Dados do universo, 2000.

Instituto Brasileiro de Geografia e Estatística. Censo demográfico de 2010. Dados do universo, 2010.

JARDIM, P. A. Reflexões sobre a mobilidade pendular. Estudo sobre deslocamentos populacionais no Brasil. Instituto Brasileiro de Geografia e Estatística. (IBGE). Rio de Janeiro, 2012.

LAMPARELLI, C. M; GEORGE, P. C. S; CAMARGO, A. R. Notas Introdutórias Sobre a Construção de um Objeto de Estudo: o Urbano. Etc. espaço, tempo e crítica: Revista Eletrônica de Ciências Sociais Aplicadas e outras coisas. N. 1(1), vol.1, maio de 2007.

LOBO, C et al. Mobilidade pendular e a integração metropolitana: uma proposta metodológica para os municípios da Região Metropolitana de Belo Horizonte/MG - 2010. Rev. bras. Est. Pop., Belo Horizonte, v.34, n.2, pp.321-339, maio/ago. 2017. https://doi.org/10.20947/S0102$\underline{3098 \mathrm{a} 0013}$

MARANDOLA JR, E; OJIMA, R. Pendularidade e vulnerabilidade na Região Metropolitana de Campinas: repercussões na estrutura e no habitar urbano. Revista Brasileira de Estudos Urbanos e Regionais (ANPUR), v. 16, pp. 185-204, 2014. https://doi.org/10.22296/23171529.2014v16n2p185

MOURA, R et al. Movimento pendular e perspectivas de pesquisas em aglomerados urbanos. In: São Paulo em perspectiva, v. 19, n. 4, pp. 121-133, out./dez. 2005. https://doi.org/10.1590/S0102$\underline{88392005000400008}$

NAKANO, A. Elementos demográficos sobre densidade urbana: São Paulo, uma cidade oca? Tese de Doutorado. Campinas, Universidade Estadual de Campinas, 2015.

NEGRI, B. Concentração e desconcentração industrial em São Paulo (1880-1990). Campinas: UNICAMP, 1996.

OJIMA, R; MARANDOLA JR., MORAES P, E; DA SILVA, R, H; BONIFÁCIO.R. O estigma de morar longe da cidade: repensando o consenso sobre as "cidades-dormitório" no Brasil. In: Cadernos Metrópole, vol. 12, núm. 24, pp. 395-415, 2010.

Fronteiras Metropolitanas: Um olhar a partir dos movimentos pendulares. Informe GEPEC (Online), v. 15, p. 615-633, 2011. 
; MARANDOLA JR. Mobilidade populacional e um novo significado para as cidades: dispersão urbana e reflexiva na dinâmica regional não metropolitana. Revista Brasileira de Estudos Urbanos e Regionais (ANPUR), v. 14, p. 103-116, 2012. https://doi.org/10.22296/2317-1529.2012v14n2p103

; MONTEIRO, F F; Tiago Carlos Lima do NASCIMENTO, T C L; Deslocamentos Pendulares e o Consumo do Espaço: explorando o tempo de deslocamento casa-trabalho. Revista Paranaense de Desenvolvimento, Curitiba, v.36, n.128, p.133-147, jan./jun. 2015.

PIKETTY, T. O capital no século XXI. 1 ed. Rio de Janeiro: Intrínseca, 2013.

RIGOTTI, J. I. R. Información de los censos demográficos del Brasil sobre migraciones internas: críticas e sugerencias para el análisis. Notas de Población, San José, n. 88, p. 219-244, 2010.

SANTOS, M. A urbanização brasileira. São Paulo, Hucitec, 1993.

Por uma economia política da cidade. São Paulo, Hucitec-EDUC, 1994.

1996.

A natureza do espaço: técnica e tempo, razão e emoção. São Paulo, Hucitec,

Por uma outra globalização: do pensamento único à consciência universal. Rio de Janeiro-São Paulo, Editora Record, 2000.

SILVA, E. Estrutura urbana e mobilidade espacial nas metrópoles. Rio de Janeiro, Observatório das Metrópoles, Letra Capital Editora, 2013.

SILVA NETO, M. L. A interação técnico-econômica do território paulista. In: $2^{\circ}$ Encontro Brasileiro de Estudos Regionais e Urbanos, 2002. Anais - 20 Encontro Brasileiro de Estudos Regionais e Urbanos. São Paulo: Associação Brasileira de Estudos Regionais, 2002.

Evolução e tendências da gestão metropolitana em São Paulo: aspectos normativos (parte 1). Arquitextos, São Paulo, n. 11.125.10, Vitruvius, out. 2010.

REIS FILHO, N. G. Notas sobre urbanização dispersa e novas formas de tecido urbano. São Paulo. Voa das Artes, 2006.

ROLNIK, R; KLINK, J. Crescimento econômico e desenvolvimento urbano: por que nossas cidades continuam tão precárias? Novos estud. - CEBRAP, São Paulo. 89, p. 89-109, Mar. 2011. https://doi.org/10.1590/S0101-33002011000100006

VASCONCELOS, A. M. N; GOMES, M. M. Transição demográfica: a experiência brasileira. Epidemiol. Serv. Saúde, Brasília, v.21, n. 4, p. 539-548, 2012. https://doi.org/10.5123/S1679$\underline{49742012000400003}$

Recebido em: 15/03/2020

Aceito para publicação em: 06/08/2020 